\title{
Metallurgical Investigation for Producing Deep-drawable Continuously Annealed Al-killed Sheet Steels through Low-temperature Coiling
}

\author{
Kohsaku USHIODA, Kazuo KOYAMA') and Manabu TAKAHASHI
}

Sheet \& Coil Research Lab., Nippon Steel Corporation, Fuchinobe, Sagamihara, Kanagawa-ken 229 Japan. Nippon Steel Corporation, Kimitsu, Kimitsu, Chiba-ken, 299-11 Japan.

1) Kimitsu R \& D Lab.,

(Received on February 14, 1990; accepted in the final form on May 18, 1990)

\begin{abstract}
Metallurgical factors for realizing the low temperature coiling at around $650^{\circ} \mathrm{C}$ of hot-rolled bands have been investigated in producing deep-drawable continuously annealed Al-killed sheet steels with a high yield rate. The following conditions are proposed: the control of the chemical compositions as i) $0.01 \%<\mathrm{C} \leqq 0.02 \%$, ii) $\mathrm{Mn} \leqq 0.15 \%$ and iii) $\mathrm{Al} \geqq 0.05 \%$, and the choice of iv) low slab reheating temperatures below $1150^{\circ} \mathrm{C}$. Conditions i) and ii) contribute to the coarsening of cementites in hot-rolled bands and to the decrease in the amount of $\mathrm{Mn}-\mathrm{C}$ complex during annealing, whilst condition iii) contributes to the promotion of AIN precipitation. These are considered to play a significant role in improving the $r$-value of the annealed sheets. Furthermore condition iv) not only has an effect on promoting grain growth due to the coarsening of precipitates in hot-rolled bands, but also contributes to the prevention of hot-shortness caused by the segregation of $S$ in austenite grain boundaries. A mechanism concerning the influence of the $\mathrm{C}$ and $\mathrm{Mn}$ contents on cementite coarsening in the hot-rolled bands is discussed, and it is concluded that the growth rate of cementite particles during coiling was retarded by the presence of $\mathrm{Mn}$. Moreover the metallurgical meanig for obtaining the excellent $r$-values is also rationalized.

A mill test based on the knowledge obtained in laboratory examination with a coiling temperature of $650^{\circ} \mathrm{C}$ resulted in a desired level of high $r$-value and less variation through a whole length of finished coil.
\end{abstract}

KEY WORDS: low-carbon steel; hot-rolling; coiling; hot-shortness; continuous annealing; formability; cementite; AIN; $\mathrm{Mn}-\mathrm{C}$ complex.

\section{Introduction}

Deep-drawable cold-rolled and annealed steel sheets are generally used for parts such as the outerpanels of automobiles which demand severe formability. In the case of deep-drawable steel sheets produced by the continuous-annealing process using low-G Al-killed steels, high temperature coiling of hot-rolled bands has been employed in order to keep the $\bar{r}$-value (index of deep-drawability) of the annealed sheets high. ${ }^{1-5}$ ) The metallurgical roles of high temperature coiling are summarized as follows:

i) coarsening of cementites and

ii) fixing $\mathrm{N}$ as AIN in hot-rolled bands.

These fundamental roles commonly contribute to the development of $\{111\}$ recrystallization texture, which is preferable from the view of deep-drawability. The role i) is played during both the cold-rolling and annealing stages as described below. Vicinities of cementite particles in cold-rolled bands are considered to be severely deformed in a highly complex manner, which leads to be preferential nucleation of recrystallized grains with random orientation. ${ }^{4,6)}$ Since these regions decrease with the reduction in number of cementite particles, the role i) becomes significant. Furthermore, cementite in cold-rolled bands is dissolved into the matrix during annealing. The dissolved $\mathrm{C}$, co-existing with $\mathrm{Mn}$, has recently been found to impair the development of $\{11\}\}$ recrystalliza- tion texture. ${ }^{7,8)}$ Role i) is also significant in the sense that the amount of harmful dissolved $\mathrm{C}$ can decrease by the reduction in number of cementite particles in hot-rolled bands..$^{1,2,8)}$ On the other hand, role ii) is presented as follows. Since fixing $\mathrm{N}$ as AlN in hotrolled bands by means of high temperature coiling leads to the decrease in the precipitation of fine AlN during annealing, the grain growth of the annealed sheets is promoted, resulting in the development of $\{111\}$ recrystallization texture.

Contrary to these beneficial metallurgical roles, high temperature coiling has the following attendant industrial shortcomings:

i) the decrease in yield caused by the degradation of mechanical properties both in the front and in the tail parts of a coil due to a relatively rapid drop in temperature in hot-rolled bands,

ii) the decrease in production efficiency caused by the difficulty in pickling the hot-rolled bands.

The present study aims to develop a technology for low temperature coiling which solves these inherent problems. Metallurgical investigations were carried out so as to maintain the formability of annealed sheets even when low temperature coiling is employed. The target for low temperature coiling was set to be $650^{\circ} \mathrm{C}$ in the present study, since preliminary examinations have indicated that the coiling of hot-rolled bands below $650^{\circ} \mathrm{C}$ prevents the attendant disadvantages with high temperature coiling. As for the pre- 
vious study of low temperature coiling, Takahashi et al..$^{9)}$ investigated the effect of $\mathrm{B}$ addition to low-C Al-killed steel. Despite the fact that B addition seems to be effective in allowing low temperature coiling in the sense that $\mathrm{B}$ fixes $\mathrm{N}$ as BN in the austenite region, it was found that B itself impaired the $\bar{r}$-value.

In the present study, metallurgical examinations were carried out to ensure the beneficial metallurgical roles of high temperature coiling even if low temperature coiling at $650^{\circ} \mathrm{C}$ was employed.

\section{Specimens and Experimental Procedures}

\subsection{Specimens}

The specimens tested were vacuum melted low-C Al-killed steels whose chemical compositions are listed in Table 1. Since the coarsening of cementite in hot-rolled bands is expected to be mostly influenced by the $\mathrm{C}$ content, the specimens with 6 different contents of $\mathrm{C}$ were used ( $\mathrm{Cl}$ to $\mathrm{C} 6$ in Table 1). On the other hand, the specimens with 4 different contents of $\mathrm{Al}$ (A1 to $\mathrm{A} 4$ in Table 1) were used because AIN precipitation in hot-rolled bands is expected to be mostly affected by the $\mathrm{Al}$ content. The $\mathrm{N}$ content, in the present study, was kept constant around 0.002 mass $\%$ (hereafter abbreviated as \%) from the viewpoint of practical steel making capability, although reducing the $\mathrm{N}$ content improves the mechanical prop-

Table 1. Chemical composition of steels used. (mass\%)

\begin{tabular}{cccccccc}
\hline Steel & G & Si & Mn & P & S & Al & N \\
\hline C 1 & 0.005 & 0.011 & 0.110 & 0.007 & 0.0070 & 0.071 & 0.0020 \\
C2 & 0.009 & 0.015 & 0.120 & 0.009 & 0.0050 & 0.063 & 0.0020 \\
C3 & 0.015 & 0.015 & 0.120 & 0.005 & 0.0060 & 0.061 & 0.0021 \\
G4 & 0.017 & 0.014 & 0.130 & 0.005 & 0.0070 & 0.056 & 0.0029 \\
C5 & 0.022 & 0.014 & 0.110 & 0.007 & 0.0060 & 0.075 & 0.0017 \\
C6 & 0.032 & 0.013 & 0.110 & 0.007 & 0.0060 & 0.073 & 0.0019 \\
\hline A1 & 0.013 & 0.013 & 0.110 & 0.005 & 0.0007 & 0.023 & 0.0023 \\
A2 & 0.013 & 0.013 & 0.110 & 0.005 & 0.0007 & 0.043 & 0.0025 \\
A3 & 0.014 & 0.013 & 0.110 & 0.005 & 0.0070 & 0.068 & 0.0026 \\
A4 & 0.013 & 0.014 & 0.110 & 0.005 & 0.0070 & 0.095 & 0.0028 \\
\hline M1 & 0.013 & 0.011 & 0.025 & 0.008 & 0.0066 & 0.054 & 0.0011 \\
M2 & 0.013 & 0.009 & 0.050 & 0.008 & 0.0069 & 0.057 & 0.0019 \\
M3 & 0.011 & 0.010 & 0.110 & 0.008 & 0.0063 & 0.059 & 0.0012 \\
M4 & 0.014 & 0.009 & 0.150 & 0.005 & 0.0057 & 0.080 & 0.0014 \\
M5 & 0.011 & 0.009 & 0.280 & 0.005 & 0.0051 & 0.070 & 0.0018 \\
M6 & 0.014 & 0.010 & 0.460 & 0.005 & 0.0056 & 0.078 & 0.0013
\end{tabular}

erties. Moreover the effect of the Mn content was examined, since a relatively large amount of $\mathrm{Mn}$ is usually added in low-C steels and the interaction between $\mathrm{Mn}$ and $\mathrm{C}$ is expected to affect the annealing textures and mechanical properties considerably. $3,7,8)$ The Mn content was varied from 0.025 to $0.46 \%$ with 6 levels (M1 to M6 in Table 1). Taking the experimental results into consideration, the contents of $\mathrm{C}$ and $\mathrm{Al}$ of the steels $\mathrm{M} 1$ to $\mathrm{M} 6$ were fixed to about 0.013 and $0.06 \%$, respectively.

\subsection{Experimental Procedures}

Slabs with a thickness of $30 \mathrm{~mm}$ were reheated to various temperatures between 1050 and $1250^{\circ} \mathrm{C}$, followed by hot-rolling and the further processing as shown in Fig. 1. The hot-rolling was finished at a temperature above $930^{\circ} \mathrm{G}$ followed by continuous cooling to $650^{\circ} \mathrm{C}$ at a cooling rate of $20^{\circ} \mathrm{C} / \mathrm{s}$, and then held for $1 \mathrm{~h}$ at this temperature and furnace-cooled at a cooling rate of about $40^{\circ} \mathrm{C} / \mathrm{h}$ to simulate low temperature coiling. However, in the case of specimens Ml to M6, the coiling simulation was carried out by reheating the hot-rolled bands to $650^{\circ} \mathrm{C}$, followed by holding for $1 \mathrm{~h}$ and furnace cooling to room temperature. Cold-rolling by $80 \%$ reduction was followed by a heat-treatment in salt baths simulating continuous annealing as shown in Fig. 1. Specimens annealed at $775^{\circ} \mathrm{C}$ for $60 \mathrm{~s}$ were air-cooled for $10 \mathrm{~s}$ followed by quenching into another salt bath at $280^{\circ} \mathrm{C}$ and held for $10 \mathrm{~min}$. The tensile properties of the annealed sheets were evaluated after temper-rolling by $1.5 \%$ reduction.

The cementite morphology in hot-rolled bands was examined by means of optical microscope after etching in a picral solution. The conventional $\mathrm{I}_{2}-\mathrm{CH}_{3} \mathrm{OH}$ method was used for the chemical analysis of AlN. Precipitates were further analysed using a $400 \mathrm{kV}$ analytical TEM. The JIS 5 type specimen in the rolling direction was used for tensile testing, whereas JIS 13B type was used for measuring the $r$-value in all 3 directions.

\section{Experimental Results}

\subsection{Morphology of Cementite in Hot-rolled Bands}

The influence of $\mathrm{C}$ on the morphology of cementite in hot-rolled bands was examined using specimens $\mathrm{Cl}$ to $\mathrm{C} 6$ in Table 1, which were reheated to $1050^{\circ} \mathrm{C}$
Fig. 1.

Diagram showing experimental procedures.

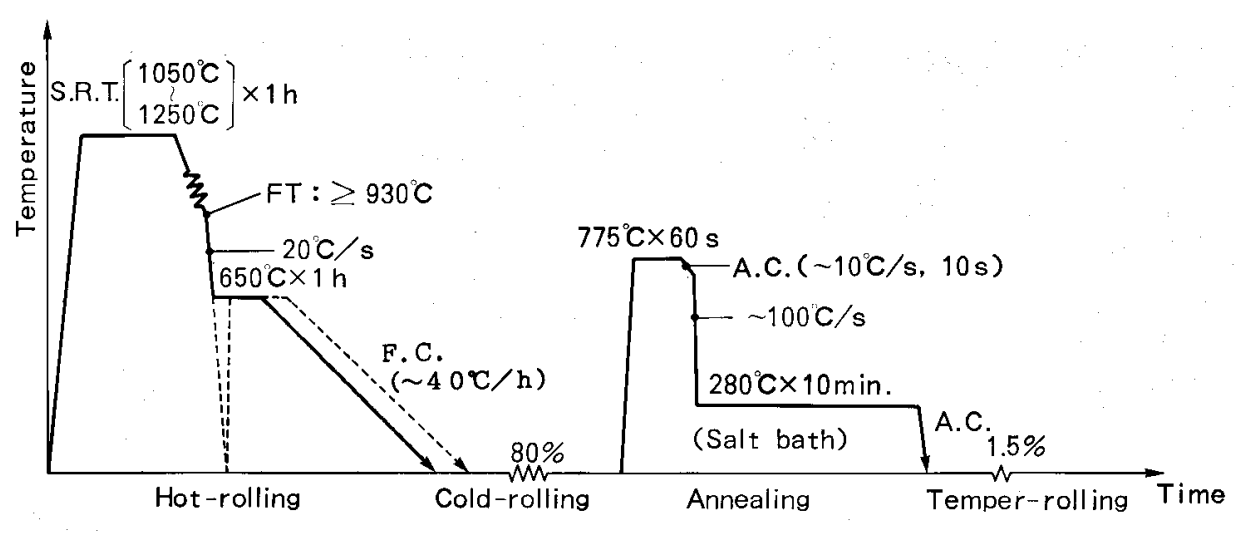


and hot-rolled followed by coiling at $650^{\circ} \mathrm{C}$. Fig. 2 shows the relationship between the inter-particle spacing of the cementite and the $\mathrm{G}$ content. The coarse dispersion of cementite particles in hot-rolled bands was achieved by lowering the $\mathrm{G}$ content below 0.02 $\%$. The inter-particle spacing of the specimen with

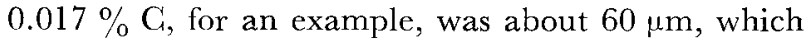
is comparable to the value about $70 \mu \mathrm{m}$ in the conventionally processed specimen $(0.03 \% \mathrm{G})$ coiled at $730^{\circ} \mathrm{C} .{ }^{8)}$ However, from the point of view of nonageing property, a lower limit of the $\mathrm{C}$ content is considered to be about $0.01 \% .{ }^{10}$

The Al content was confirmed as not influencing the coarsening of cementite in the hot-rolled bands coiled at $650^{\circ} \mathrm{C}$ within the range examined (A1 to A4 in Table 1).

The influences of $\mathrm{Mn}$ content and slab reheating temperature on the coarsening of cementite in hotrolled bands were represented in Figs. 3 and 4 (M1 to M6 in Table 1). The decrease in Mn content, especially below $0.1 \%$, is distinctivcly effective in the coarsening of cementite, whilst the slab reheating temperature has almost no effect on it.

The mechanisms involving the effect of $\mathrm{G}$ and $\mathrm{Mn}$ on cementite coarsening will be discussed in Secs. 5.1 and 5.2 .

\subsection{Precipitation of $\mathrm{AlN}$ in Hot-rolled Bands}

The influence of $\mathrm{Al}$ content on the precipitation ratio of AIN (N as AIN/Total N) in hot-rolled bands was investigated using specimens $\mathrm{Al}$ to $\mathrm{A} 4$ in Table 1. It was found that the increase in $\mathrm{Al}$ content, more

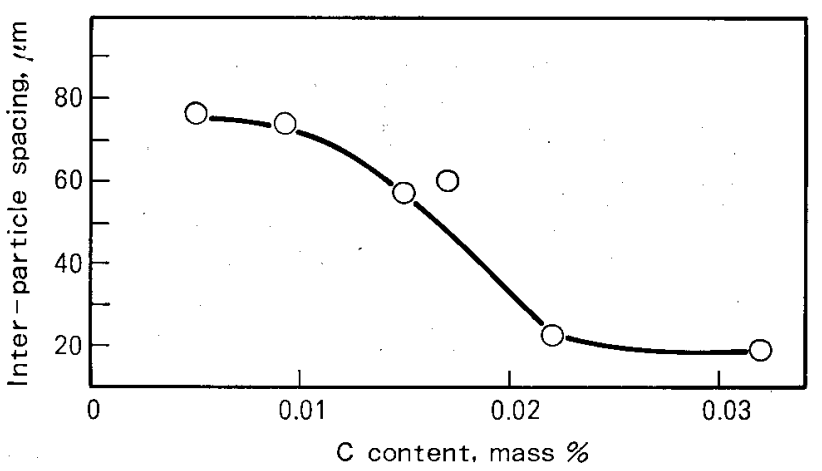

Fig. 2. Changes in inter-particle spacing of cementite with $\mathrm{C}$ contents in hot-rolled bands coiled at $650^{\circ} \mathrm{C}$. (Steels C.1-G6) than $0.05 \%$, makes it possible to fix more than $70 \%$ of total $\mathrm{N}$ as AlN even if hot-rolled bands are coiled at $650^{\circ} \mathrm{C}$. This is rather close to that coiled at a high temperature $\left(e . g ., 730^{\circ} \mathrm{C}\right)$. Furthermore lower slab reheating temperatures tend to fix more $\mathrm{N}$ as AlN.

The extraction replica images of the precipitates observed in hot-rolled bands are shown in Fig. 5. The globular precipitates observed in the specimen Al, namely $0.023 \% \mathrm{Al}$, was confirmed to be $\mathrm{MnS}$ (Fig. 5(a)), whereas, the precipitates observed in specimen A3, namely $0.068 \% \mathrm{Al}$, are similar to those observed in specimen $A l$ with respect to their size and distribution (Fig. 5(b)). However, they have a rather angular shape and were confirmed to be the compound precipitates of $(\mathrm{MnS}+\mathrm{AlN})$ based on the energy dispersive $\mathrm{X}$-ray analyses and electron diffraction patterns. The frequency of observing the compound precipitates of $(\mathrm{MnS}+\mathrm{AlN})$ increases with increasing Al content as shown in Fig. 6. Moreover higher slab reheating of the specimen $\mathrm{A} 3$ up to $1250^{\circ} \mathrm{C}$ resulted in a large number of fine precipitates in hot-rolled bands (Fig. 5(c)). They were also confirmed to be the compound precipitates of $(\mathrm{MnS}+\mathrm{AlN})$.

According to Leslie et al., ${ }^{11}$ the solution temperature of $\mathrm{MnS}$ in the specimen $\mathrm{Al}$ to $\mathrm{A} 4$ is $1153^{\circ} \mathrm{C}$,

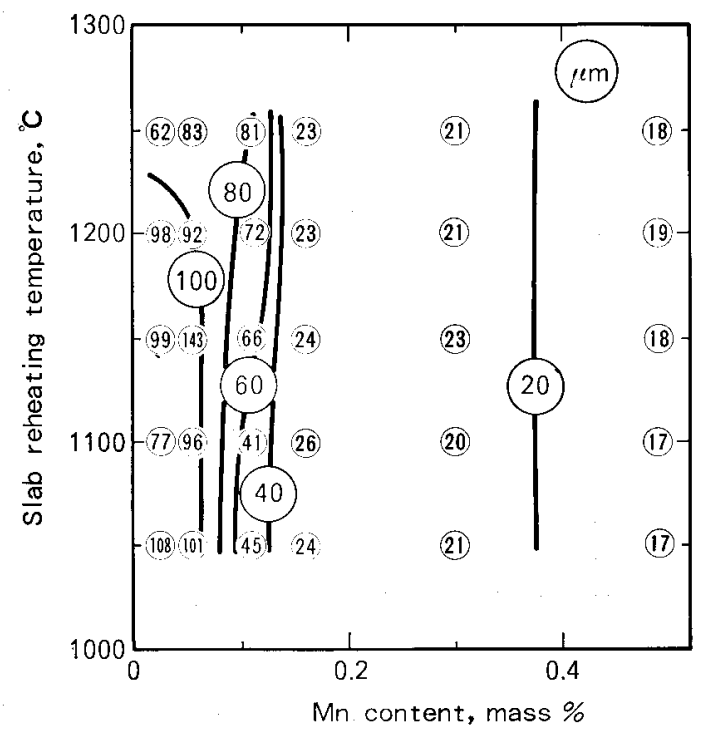

Fig. 4. Influences of $\mathrm{Mn}$ content and slab reheating temperature on inter-particle spacing of cementite in hot-rolled band coiled at $650^{\circ} \mathrm{C}$. (Steels M1-M6).

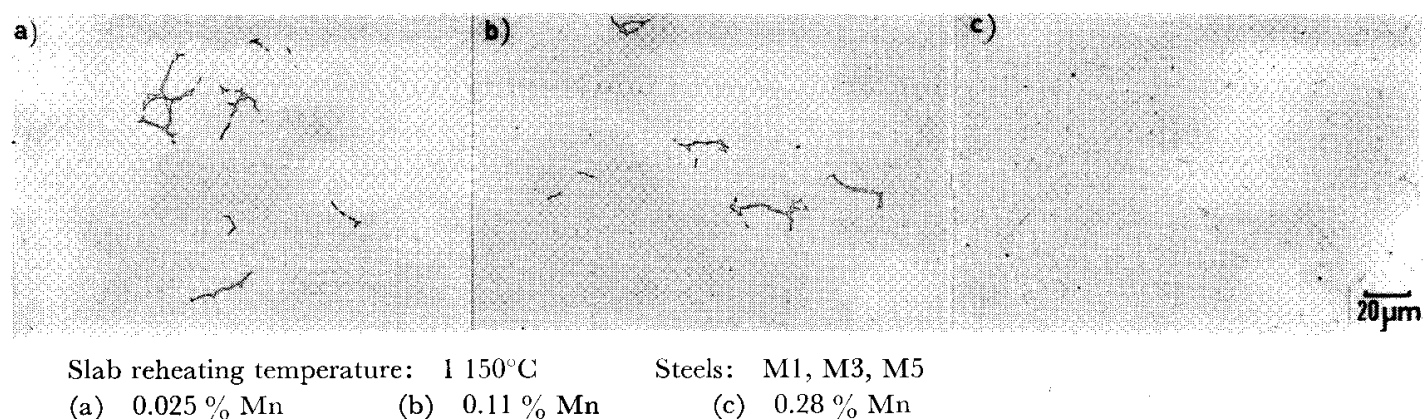

Fig. 3. Optical micrographs showing the influence of $\mathrm{Mn}$ content on cementite coarsening in hot-rolled bands coiled at $650^{\circ} \mathrm{C}$. 
whilst those of AlN in specimen A1 $(0.023 \%)$ and A3 $(0.068 \%)$ are calculated to be 1002 and $1142^{\circ} \mathrm{C}$, respectively. Therefore, it is considered that the larger compound precipitates observed in the specimens with high $\mathrm{Al}$ content (e.g., A3) are formed during the slab reheating stage, when low slab reheating temperatures of $1050^{\circ} \mathrm{C}$ are used. In the case of high slab reheating temperatures of $1250^{\circ} \mathrm{C}$, it is speculated that the dissolved $\mathrm{MnS}$ precipitates again very finely during hot-rolling followed by the precipitation of AlN on them. When the $\mathrm{Al}$ content is low such as in the specimen $\mathrm{Al}, \mathrm{Al}$ can hardly fix $\mathrm{N}$ as AIN in hot-rolled bands coiled at low temperature, which results in the single precipitates as $\mathrm{MnS}$. Therefore the addition of amounts of $\mathrm{Al}$ of more than $0.05 \%$ is considered to be very effective in fixing $\mathrm{N}$ as AlN.

\subsection{Tensile Properties of Annealed Sheets}

In general, the decrease in coiling temperature tends to impair formability, for instance, the deterioration of $\bar{r}$-value, the rise in yield strength and the decrease in elongation. However, Fig. 7 demonstrates that the decrease in Mn content of the specimens with $\mathrm{G} \leqq 0.02 \%$ and $\mathrm{Al} \geqq 0.05 \%$ and the reduction in the slab reheating temperature have a marked effect on improving formability with regard to the $\bar{r}$-value, yield strength and elongation (steels Ml to M6). These results are inferred to be closely related to the coarsening of cementite and the precipitation of $\mathrm{AlN}$ in hot-rolled bands as well as the decrease in the content of $\mathrm{Mn}-\mathrm{G}$ complex during annealing, which will be discussed in Sec. 5.3.

\subsection{Hot-shortness in the Edge of Hot-rolled Bands}

The reduction in $\mathrm{Mn}$ content has been shown to play a significant part in improving the mechanical properties of the final products. On the other hand, it has a shortcoming with regard to the hot-shortness. Fig. 8 shows the influences of $\mathrm{Mn}$ content and slab reheating temperature on the hot-shortness. It is evident that the reduction in the slab reheating temperature has a significant effect in preventing the embrittlement caused by lowering the Mn content. For example, in the case of the specimen with $0.1 \%$ $\mathrm{Mn}$ and $0.007 \% \mathrm{~S}$, no hot-shortness was observed when reducing the slab reheating temperature below $1150^{\circ} \mathrm{C}$

\section{Result of Practical Mill Test for Low Tem- perature Coiling}

Based upon the findings described in Chap. 3, a practical mill testing for low temperature coiling was carried out. Table 2 shows the chemical composi-

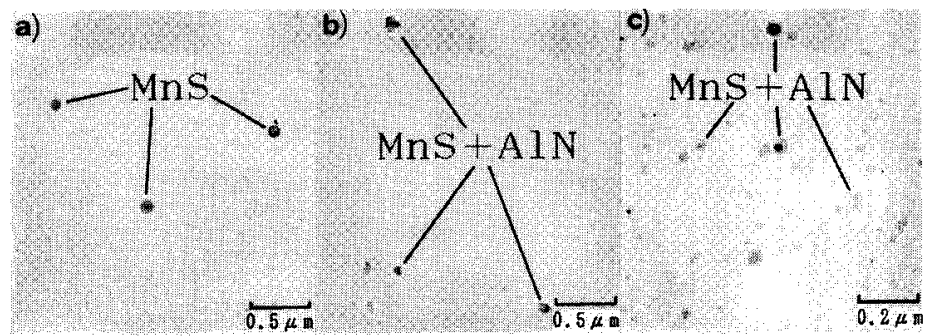

(a) Steel Al $(0.023 \% \mathrm{Al})$, SRT: $1050^{\circ} \mathrm{C}$

(b) Steel A3 $(0.068 \% \mathrm{Al})$, SRT: $1050^{\circ} \mathrm{C}$

(c) Steel A3 $(0.068 \% \therefore \mathrm{il})$, SRT: $1250^{\circ} \mathrm{C}$

SRT: Slab reheating temperature

Fig. 5. TEM observation of extraction replica of precipitates in hotrolled band coiled at $650^{\circ} \mathrm{C}$.

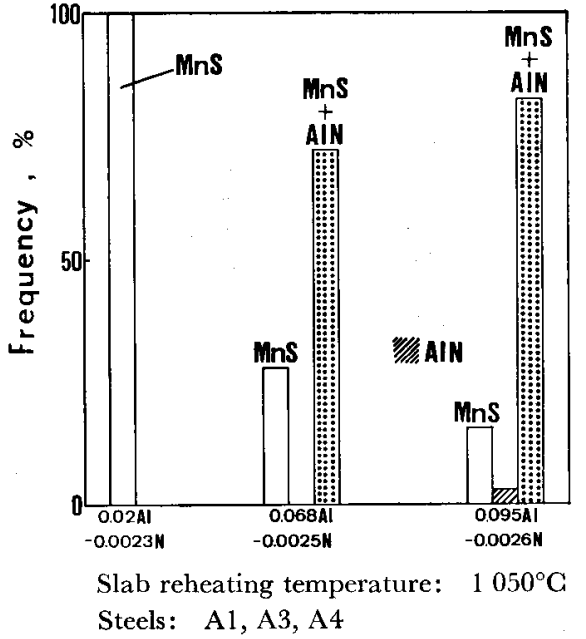

Fig. 6. Influence of A1 content on the composition of precipitates in hot-rolled bands coiled at $650^{\circ} \mathrm{C}$.

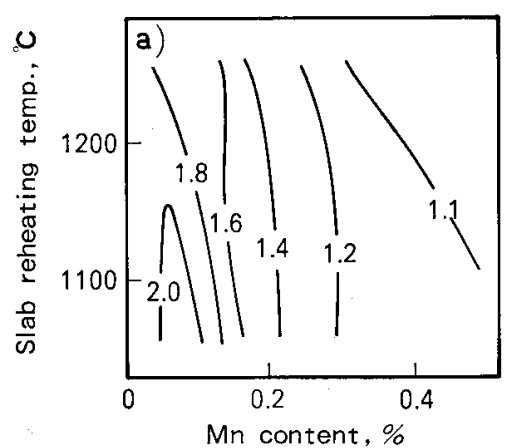

Coiling temperature: $650^{\circ} \mathrm{C}$
(a) $\bar{r}$
(b) $Y P$
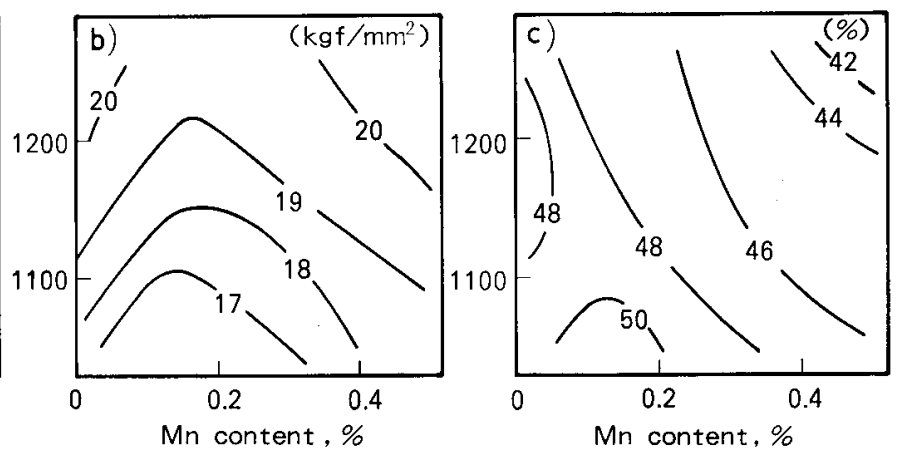

Steels: $\mathbf{M} 1-\mathbf{M} 6$

(c) $E l$

Fig. 7. Influences of $\mathrm{Mn}$ content and slab rehating temperature on tensile properties of annealed sheets. 
Table 2. Chemical composition and processing condition of mill-tested steels.

\begin{tabular}{|c|c|c|c|c|c|c|c|c|c|c|c|}
\hline \multicolumn{6}{|c|}{ Chemical composition (mass\%) } & \multicolumn{3}{|c|}{ Hot-rolling $\left({ }^{\circ} \mathrm{C}\right)$} & \multirow{2}{*}{$\begin{array}{l}\text { Cold-rolling } \\
\text { reduction } \\
(\%)\end{array}$} & \multirow{2}{*}{$\begin{array}{l}\text { Annealing } \\
\left({ }^{\circ} \mathrm{G}-\mathrm{s}\right)\end{array}$} & \multirow{2}{*}{$\begin{array}{l}\text { Temper- } \\
\text { rolling } \\
\text { reduction } \\
(\%)\end{array}$} \\
\hline $\mathrm{C}$ & $\mathrm{Mn}$ & $\mathbf{P}$ & $\mathrm{S}$ & AI & $\mathbf{N}$ & SRT & FT & GT & & & \\
\hline 0.016 & 0.09 & 0.004 & 0.006 & 0.068 & 0.0015 & 1070 & 915 & 650 & 80 & $780-60$ & 1.0 \\
\hline
\end{tabular}

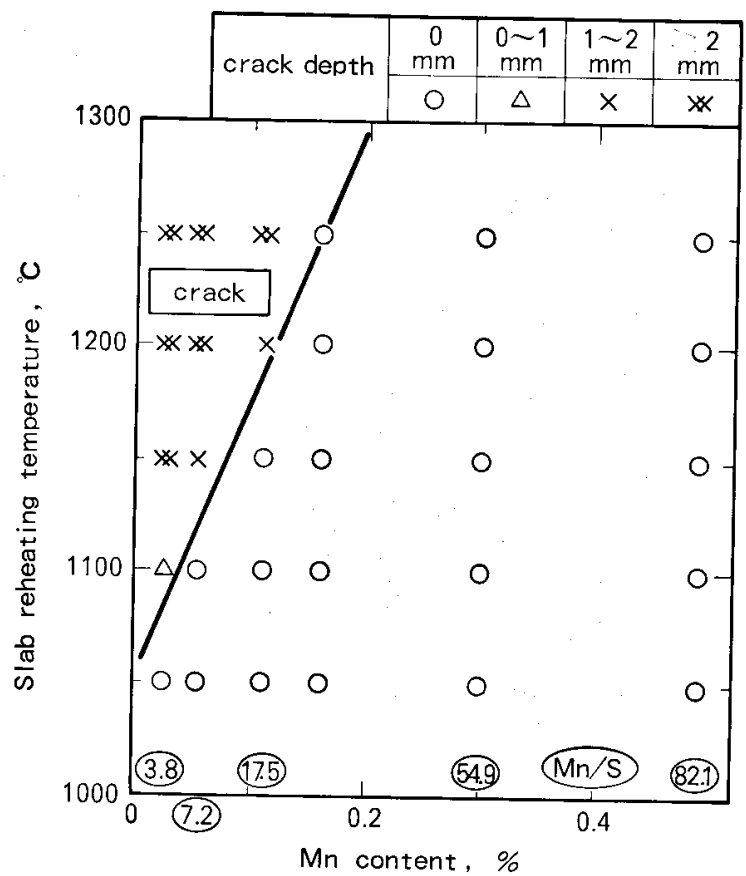

Fig. 8. Influences of $\mathrm{Mn}$ content and slab reheating temperature on the hot-shortness in hot-rolled bands. (Steels M1-M6)

Crack depth in the figure denotes the length of crack measured from the width-edge of hot-rolled bands.

tions and the production conditions from hot-rolling to temper-rolling of the steel tested. The coiling temperature was $650^{\circ} \mathrm{C}$. Fig. 9 shows the along-thelength distribution of the $\bar{r}$-value of the final product, which is very significant from the industrial point of view. For the purpose of comparison, a representative result in the case of the conventional steel with about $0.03 \% \mathrm{C}, 0.2 \% \mathrm{Mn}$, and $0.03 \% \mathrm{Al}$ coiled at $750^{\circ} \mathrm{C}$ was also plotted in the same figure. It is evident that by employing low temperature coiling based on the present proposal, not only is the level of $\bar{r}$ value obtained sufficiently high, but also is the alongthe-length distribution significantly improved.

\section{Discussion}

\subsection{Mechanism of Cementite Coarsening in Hot-rolled Bands}

\subsubsection{Influence of $\mathrm{C}$ Content}

Cementite in hot-rolled bands forms during rapid cooling on the run-out-table after hot-rolling and/or during slow cooling after coiling.

Firstly the phase transformation and the cementite precipitation behaviors during continuous cooling from a single austenite region were experimentally investigated, taking into account the fact that the

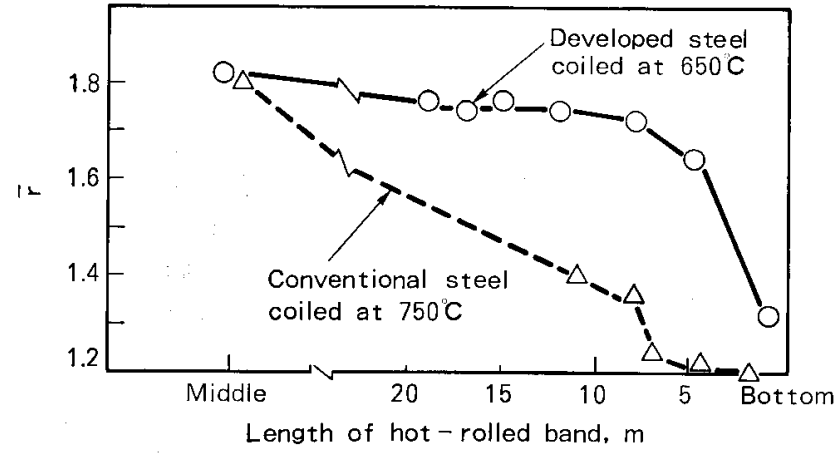

Fig. 9. Comparison of along-the-length distribution of $\bar{r}$ value of annealed sheets tested in a production scale.

The developed steel listed in Table 2 were coiled at $650^{\circ} \mathrm{C}$, whilst the conventional steel with about $0.03 \% \mathrm{C}, 0.2 \% \mathrm{Mn}$ and $0.03 \% \mathrm{Al}$ were coiled at $750^{\circ} \mathrm{C}$.

cooling rate in the practical run-out-table is about $20^{\circ} \mathrm{C} / \mathrm{s}$. The specimens used were low-C and low-Mn Al-killed steels with 2 different $\mathrm{C}$ contents, i.e., 0.012 $\% \mathrm{G}$ and $0.038 \% \mathrm{C}$, whose chemical compositions are listed in Table 3 . The specimens were rcheated once to $930^{\circ} \mathrm{C}$ in the austenite region and held for 20 min followed by continuous cooling at a rate of $20^{\circ} \mathrm{C} / \mathrm{s}$. The microstructural changes during cooling were examined using optical microscope for the specimens quenched from various temperatures during cooling.

In the specimen with $0.012 \% \mathrm{C}$, cementite commences to precipitate in the ferrite grain boundaries at round $560^{\circ} \mathrm{C}$ after the completion of phase transformation from $\gamma$ to $\alpha$ (Figs. 10(a) and 10(b)). In the specimen with $0.038 \% \mathrm{G}$, on the contrary, pearlite transformation starts at around $690^{\circ} \mathrm{C}$ followed by its growth during cooling (Figs. 10(c) and 10(d)). Based upon these experimental data, it is possible to draw schematic CC'T curves (Fig. 11). As Seter et al. ${ }^{12}$ and, recently Shimohigashi et al..$^{13)}$ have pointed out, steels with more than $0.02 \% \mathrm{C}$ have pearlite transformation on the run-out-table resulting in the fine pearlite nodules in hot-rolled bands coiled at low temperature (Fig. 11(c)). The steel with less than $0.02 \% \mathrm{C}$ is thought conversely to form coarse cementite particles in hot-rolled bands even when they are coiled at $650^{\circ} \mathrm{C}$, since cementite starts to precipitate in ferrite grain boundaries during slow cooling after coiling (Fig. 1l(b)). Therefore it is necessary to reduce the $\mathrm{C}$ content to less than $0.02 \%$ in order to obtain coarse cementite in hot-rolled bands coiled at $650^{\circ} \mathrm{C}$.

\subsubsection{Influence of Mn Content}

Cementite in hot-rolled bands coiled at $650^{\circ} \mathrm{C}$ 
tends to aggregate with decreasing Mn content, the mechanism of which is discussed here. Since the preferred steels contain less than $0.02 \% \mathrm{C}$, cementite is supposed to precipitate in ferrite grain boundaries of hot-rolled bands after the completion of the phase transformation from $\gamma$ to $\alpha$. Cementite is assumed to form by the nucleation and growth mechanism.

The influence of $\mathrm{Mn}$ on the solubility of $\mathrm{C}$ in ferrite which is in equilibrium with cementite is of most importance, since the solubility is closely related to

Table 3. Chemical composition of steels used. (mass\%)

\begin{tabular}{lccccccc}
${ } }$ & $\mathrm{C}$ & $\mathrm{Si}$ & $\mathrm{Mn}$ & $\mathrm{P}$ & $\mathrm{S}$ & $\mathrm{Al}$ & $\mathrm{N}$ \\
\hline LC & 0.012 & $<0.010$ & 0.07 & 0.007 & 0.0081 & 0.073 & 0.0024 \\
$\mathrm{MC}$ & 0.038 & $<0.010$ & 0.08 & 0.008 & 0.0083 & 0.074 & 0.0017 \\
\hline
\end{tabular}

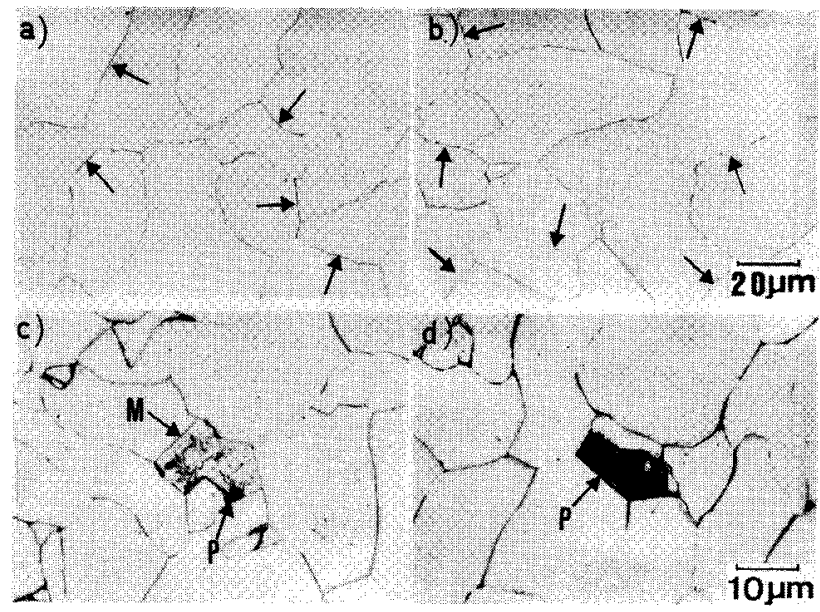

Fig. 10. Optical micrographs showing the precipitation of grain boundary cementite (arrows) and pealite during continuous cooling $\left(20^{\circ} \mathrm{C} / \mathrm{s}\right)$ after isothermal annealing at $930^{\circ} \mathrm{C}$ for $20 \mathrm{~min}$ to the following temperatures: (a) $559^{\circ} \mathrm{C}$, (b) $521^{\circ} \mathrm{C}$ for steel $\mathrm{LG}$, and (c) $690^{\circ} \mathrm{C}$, (d) $676^{\circ} \mathrm{C}$ for steel MC. the temperature at which cementite commences to precipitate. One of the present authors reported that Mn hardly affects the solubility. ${ }^{14)}$ Therefore, the commencing temperature of cementite precipitation is assumed almost independent of Mn content, as long as the $\mathrm{G}$ content is identical.

Taking into consideration the fact that the nucleation site of cementite is the ferrite grain boundary, the influence of $\mathrm{Mn}$ on the following two factors with respect to the nucleation process becomes important:

a) the ferrite grain size, and

b) the distribution density of precipitates such as $\mathrm{MnS}$ in the ferrite grain boundaries of hot-rolled bands.

Firstly, it was confirmed that the grain size of hotrolled bands is scarcely affected by the presence of Mn, namely, about 20 to $25 \mu \mathrm{m}$ for all the specimens. This negates the possibility of condition a) mentioned above. Secondly the variation in the distribution density of precipitates with $\mathrm{Mn}$ content in hot-rolled bands is demonstrated in Fig. 12. The slab reheating temperature was identical at $1100^{\circ} \mathrm{G}$ in the both cases. It is evident that the distribution density of precipitates supposed as MnS increases with decreasing Mn content. Supposing that the precipitates in grain boundaries act as the preferential nucleation sites of cementite, ${ }^{15)}$ coarse cementite particles are expected to form by increasing the Mn content. This expectation is in complete disagreement with the experimental observations shown in Figs. 3 and 4 . Therefore, the factor b) as a mechanism can also be disregarded. This conclusion is further supported by the fact that cementite coarsening is not affected by the slab reheating temperature despite the decrease in the distribution density of precipitates by reducing the slab reheating temperature.

Next, the influence of $\mathrm{Mn}$ on cementite coarsening is discussed from the aspect of the growth of cementite. The factors affecting the growth rate are classified as

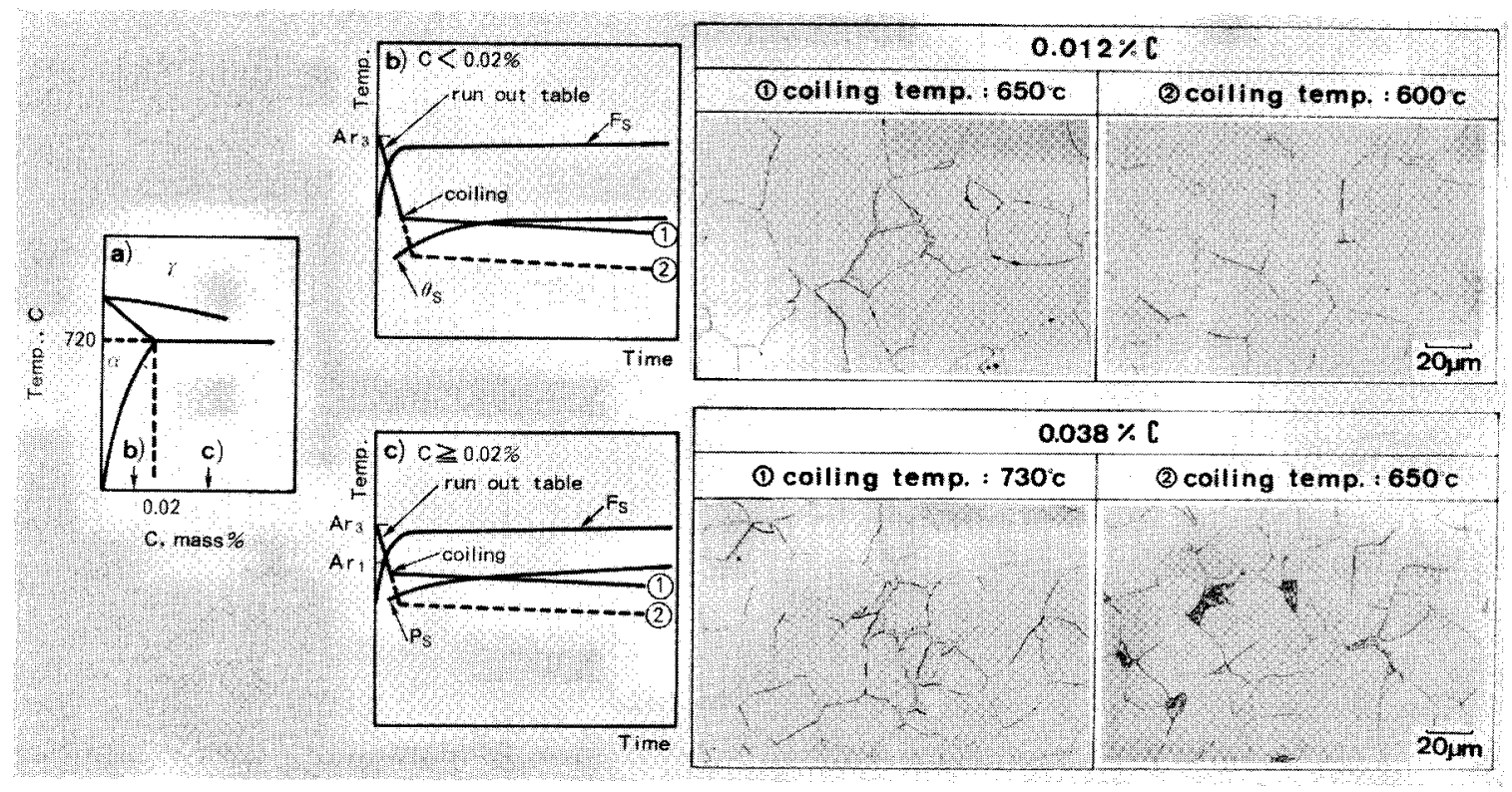

Fig. 11. Schematic illustration of CCT curves for two low-C steels showing the influences of $\mathrm{C}$ content and coiling temperature on cementite coarsening. 


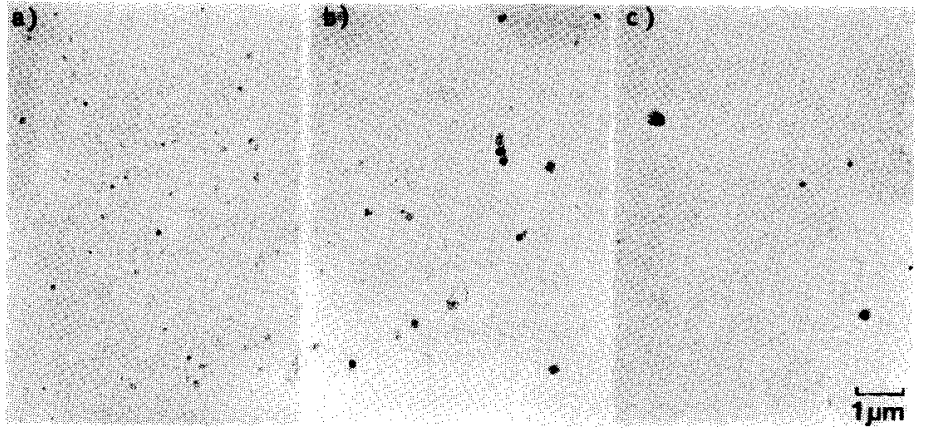

Slab reheating temperature: $1100^{\circ} \mathrm{C}$
(a) $0.05 \% \mathrm{Mn}$
(b) $0.11 \% \mathrm{Mn}$
(c) $0.28 \% \mathrm{Mn}$

Steels: M2, M3, M

Fig. 12. TEM observation of extraction replica showing the influence of $\mathrm{Mn}$ content on precipitates in hot-rolled bands coiled at $650^{\circ} \mathrm{C}$.

follows:

a) influence of $\mathrm{Mn}$ on $\mathrm{C}$ diffusion in ferrite,

b) influence of $\mathrm{Mn}$ on the growth rate of cementite due to the partitioning of the slower diffuser $\mathrm{Mn}$ between ferrite and cementites.

Regarding factor a), no reliable experimental data are thought to be available. Nishizawa ${ }^{16)}$ investigated the influence of a third element on $\mathrm{G}$ diffusion in austenite thermodynamically. In the present study, his analysis was extended to the case of ferrite. The presence of the third element $(M)$ modifies the diffusivity of $\mathrm{C}$ in ferrite as described in Eq. (1),

$$
D_{\mathrm{C}}^{M}=D_{\mathrm{C}}\left(1-\frac{W_{M C}}{R T} \cdot x_{M} \cdot x_{\mathrm{C}}\right),
$$

where, $D_{\mathrm{C}}, D_{\mathrm{C}}^{M}$ : the diffusion coefficients of $\mathrm{G}$ in $\mathrm{Fe}-\mathrm{C}$ and in $\mathrm{Fe}-\mathrm{C}-\mathrm{M}$ systems, respectively

$W_{M C}:$ the interaction parameter between $M$ and $\mathrm{C}$ atoms

$x_{M}, x_{\mathrm{C}}$ : the atomic fraction of $M$ and $\mathrm{C}$ atoms, respectively.

Substituting $x_{M}=3.0 \times 10^{-3}(0.3 \% \mathrm{Mn}), x_{\mathrm{C}}=9.3 \times 10^{-4}$ $(0.02 \% \mathrm{C}), W_{3 \mathrm{C}}=0.26 \mathrm{eV}^{17)}$ and $T=923 \mathrm{~K}$ into Eq. (1), $D_{\mathrm{C}}^{M}$ was found to be almost the same as $D_{\mathrm{C}}$. Therefore, factor a) mentioned above is concluded not to be significant.

The mechanism of the influence of $\mathrm{Mn}$ on the growth rate of cementite is discussed with respect to factor $\mathrm{b}$ ). The line chemical analyses of cementite in hot-rolled bands coiled at $650^{\circ} \mathrm{C}$ by means of EPMA reveal that $\mathrm{Mn}$ enriched to cementite in the specimen M5 containing $0.28 \% \mathrm{Mn}$ (Fig. 13). The enrichment of $\mathrm{Mn}$ was observed in a number of cementite particles. Although EPMA allows us only semi-quantitative evaluation in terms of the amount of the enrichment, the content of $\mathrm{Mn}$ in cementite was roughly evaluated to be $1 \%$ for the specimen with 0.28 $\% \mathrm{Mn}$. According to Hillert et al. ${ }^{18)}$ the equilibrium content of $\mathrm{Mn}$ in cementite at $650^{\circ} \mathrm{C}$ is expected to be $4.5 \%$ using the partitioning coefficient with the value of about 15. The partitioning of $\mathrm{Mn}$ between ferrite and cementite has the possibility of retarding the growth rate of cementite. In the present study, the growth rate is evaluated as follows. Fig. 14 shows
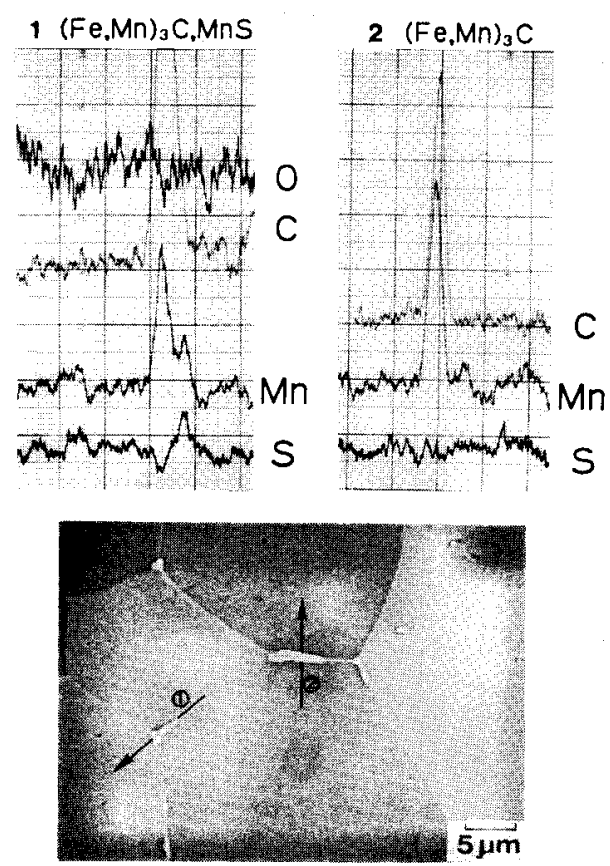

Fig. 13. EPMA analyses showing the enrichment of $\mathrm{Mn}$ in cementite in hot-rolled band coiled at $650^{\circ} \mathrm{C}$. (Steel M5)

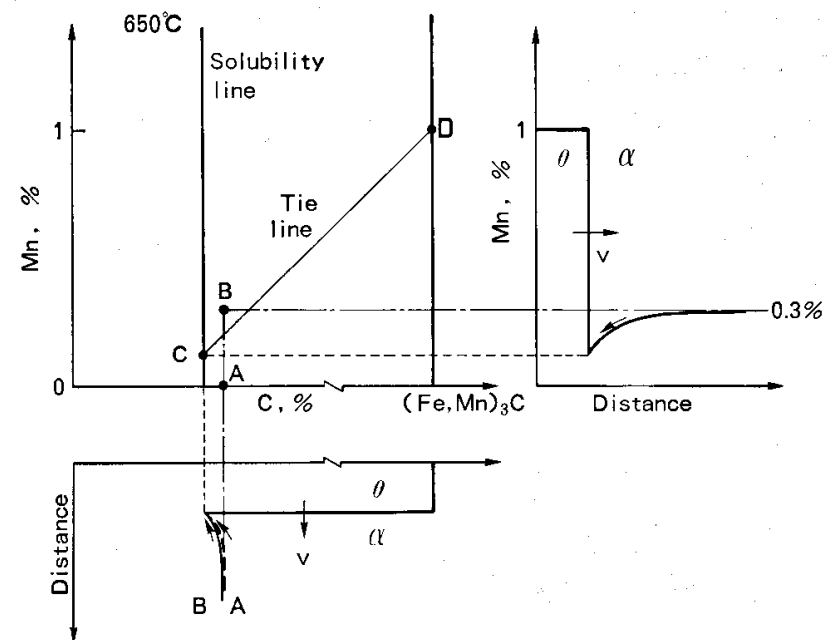

Fig. 14. Schematic illustration of isothermal compositional section showing the influence of $\mathrm{Mn}$ on the growth rate of cementite.

the isothermal compositional section at $650^{\circ} \mathrm{C}$. Supposing that

i) the steels considered here contain 0 and $0.3 \%$ $\mathrm{Mn}$, as described $A$ and $B$ in Fig. 14, respectively, ii) cementite grows with the common supersaturation of $\mathrm{C}$ with the amount of 20 ppm.

Firstly, in steel $\mathrm{A}$, the growth rate of cementite, $v$ $\left(\mathrm{cm} \cdot \mathrm{s}^{-1 / 2}\right)$, can be evaluated using Eq. (2) which was proposed by Coates, ${ }^{19)}$ based on the mass conservation of $\mathrm{C}$ at the growing interface,

$$
\begin{aligned}
\frac{\bar{C}-C^{\alpha \theta}}{C^{\theta}-C^{\alpha \theta}}= & \sqrt{\frac{\pi}{4 D_{\mathrm{C}}}} \cdot v \cdot\left[1-\operatorname{erf}\left(-\frac{v}{\sqrt{4 D_{\mathrm{C}}}}\right)\right] \\
& \cdot \exp \left(\frac{y^{2}}{4 D_{\mathrm{C}}}\right), \quad \ldots \ldots \ldots \ldots \ldots \ldots \ldots \ldots \ldots \ldots \ldots \ldots \ldots
\end{aligned}
$$

where, $\bar{C}$ : the average $\mathrm{C}$ content in matrix 
$C^{\alpha \theta}$ : the equilibrium $\mathrm{G}$ content in ferrite at the $\alpha / \theta$ interface

$C^{\theta}$ : the equilibrium $\mathrm{C}$ content in cementite

$D_{\mathrm{C}}$ : the diffusion coefficient of $\mathrm{C}$ in ferrite.

In Eq. (2), i) one dimensional parabolic growth rate, and ii) no soft impingement during growth were assumed. The growth rate of cementite (v) in steel A was evaluated to be $3.8 \times 10^{-7} \mathrm{~cm} \cdot \mathrm{s}^{-1 / 2}$. Furthermore, Coates ${ }^{19}$ ) reported a similar approach in ternary alloys (Fe-C-M) like the steel B. Assuming local equilibrium, the growth rate of cementite was determined so as to satisfy the mass balance at the $\alpha / \theta$ interface with respect to both $\mathrm{C}$ and $\mathrm{Mn}$ atoms. The growth rate $(v)$ in steel $B$ was calculated to be $4.1 \times$ $10^{-8} \mathrm{~cm} \cdot \mathrm{s}^{-1 / 2}$. The tie line was determined to be the line $C D$ as described in Fig. 14. The absolute values of the growth rates were found out to be lower than the actual values, since the bulk diffusivities of $\mathrm{C}$ and $\mathrm{Mn}$ atoms were used. However, the relative comparison is considered to be acceptable. It was clarified that the addition of Mn up to $0.3 \%$ may retard the growth rate of cementite by the order of one because of the enrichment of $\mathrm{Mn}$ atoms in the cementite. Therefore, it is natural to speculate that in the case of steels with the addition of $\mathrm{Mn}$, cementite particles in hot-rolled bands tend to be finely distributed due to the retardation of the growth of cementite, even if the nucleation of cementite particles themselves are not affected.

\subsection{Factors Affecting $\bar{r}$-value of Annealed Sheets}

The optimization of the steel chemistry as well as the hot-rolling conditions was found to ensure the high formability of continuously annealed sheets even if the hot-rolled bands were coiled at a low temperature. The metallurgical meanings for this technology are summarized in Fig. 15. Firstly, control of the chemical composition as $\mathrm{G} \leqq 0.02 \%$ and $\mathrm{Mn} \leqq 0.15 \%$ contributes to the coarsening of cementite in hotrolled bands coiled at $650^{\circ} \mathrm{C}$. The coarse cementite particles are considcred to be beneficial for the following two reasons:

i) the decrease in the nucleation rate of the randomly oriented recrystallized grains ${ }^{4,6)}$

ii) the decrease in the content of $\mathrm{Mn}-\mathrm{C}$ complex during annealing because of the lower content of the redissolved $\mathrm{C}$ and the lower addition of Mn. ${ }^{7,8)}$

These two conditions i) and ii) contribute to the development of $\{111\}$ recrystallization texture. Moreover the addition of more than $0.05 \% \mathrm{Al}$ can fix $\mathrm{N}$ as AIN considerably, resulting in the decrease in fine AlN which precipitates during annealing. High Al additions together with factor ii) mentioned above contribute to the grain growth of ferrite in the annealed sheets. The grain growth is further promoted by the low slab reheating temperature which leads to the coarsening of the compound precipitates such as $(\mathrm{MnS}+\mathrm{AlN})$. Since the grain growth results in the development of $\{111\}$ recrystallization texture, all of these are considered to contribute to the improvement of deep-drawability of the steel.

\subsection{Effect of Low Slab Reheating Temperature on the Prevention of Hot-shortness}

The decrease in the slab reheating temperature prevents the hot-shortness of hot-rolled bands as shown in Fig. 8. The observation of the fracture surface by means of SEM allowed us to speculate on the mechanism as the liquid film embrittlement of austenite grain boundaries, the reason for which is as follows. In the case where the Mn content decreases too much and/or the slab reheating temperature increases high enough to dissolve $\mathrm{MnS}$, the content of $\mathrm{S}$ unfixed by $\mathrm{Mn}$ as $\mathrm{MnS}$ increases. Since $\mathrm{S}$ has a tendency to segregate into grain boundaries, the con-

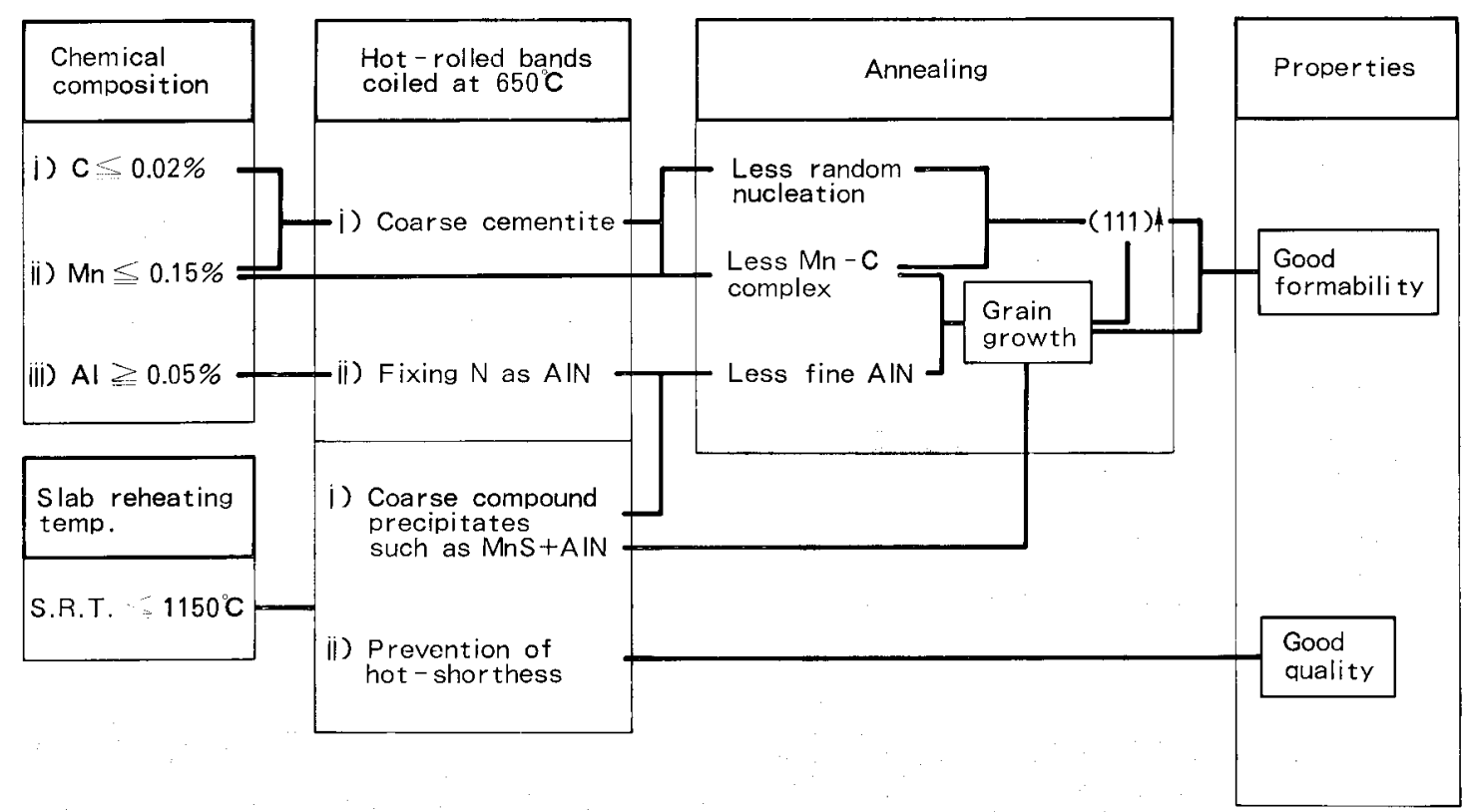

Fig. 15. Schematic diagram showing a method and metallurgical meanings to produce deep-drawable continuously annealed sheet through a low temperature coiling at $650^{\circ} \mathrm{C}$. 
tent of $\mathrm{S}$ in the austenite grain boundaries is supposed to become significantly high. Taking into consideration the fact that the molten steel with the high content of $\mathrm{S}$ has a eutectic reaction at $988^{\circ} \mathrm{C}$, the existence of the liquid film in the austenite grain boundaries is expected above the eutectic temperature which causes hot-shortness. ${ }^{20)}$

\section{Conclusions}

For the production of the deep-drawable coldrolled and continuously annealed Al-killed steel sheets using the hot-rolled bands coiled at around $650^{\circ} \mathrm{G}$, the following conditions are proposed: the control of chemical compositions as i) $0.01 \%<\mathrm{C} \leqq 0.02 \%$, ii) $\mathrm{Mn} \leqq 0.15 \%$ and iii) $\mathrm{Al} \geqq 0.05 \%$, and the choice of iv) low slab reheating temperatures below $1150^{\circ} \mathrm{C}$. Conditions i) and ii) contribute to the coarsening of cementite in hot-rolled bands and to the decrease in the content of $\mathrm{Mn}-\mathrm{C}$ complex during annealing, whilst condition iii) contributes to the promotion of AlN precipitation. These are considered to play a significant role in improving the $\vec{r}$-value of the annealed sheets. Furthermore condition iv) not only has an effect on promoting grain growth due to the coarsening of precipitates in hot-rolled bands, but also contributes to the prevention of hot-shortness in hotrolled bands caused by $\mathrm{S}$.

Based upon the knowledge obtained from laboratory experiments, a mill testing was carried out. This confirmed that the proposed conditions maintain a constantly high $\bar{r}$-value through the whole length of coil employing the low temperature coiling at $650^{\circ} \mathrm{C}$.

\section{Acknowledgments}

The authors express their thanks to Drs. H. Takechi, H. Katoh and O. Akisue in Nippon Steel Corporation for their valuable discussion and suggestions. Thanks are also extended to Mr. A. Shimohigashi in Nagoya Works of Nippon Stecl Corporation for his valuable comments and active cooperation.

\section{REFERENCES}

1) H. Kubodera, K. Nakaoka, K. Araki, K. Watanabe and K. Iwase: Tetsu-to-Hagané, 62 (1976), 846.

2) K. Matsudo, T. Shimomura and O. Nozoe: Tex. Cryst. Solids, 3 (1978), 53.

3) K. Toda, H. Gondoh, H. Takechi, M. Abe, N. Uehara and K. Komiya: Trans. Iron Steel Inst. Jpn., 15 (1975), 305.

4) M. Matsuo, H. Hayakawa and S. Hayami: Proc. of Int. Conf. of Textures and Materials, ed. by G. Gottstein and K. Lücke, Springer-Verlag, Berlin, (1978), 275.

5) P. Mould: Proc. Conf. on Metallurgy of ContinuousAnnealed Sheet Steel, ed. by B. L. Bramfitt and P. L. Mangonon, Jr., AIME, Dallas, TX, (1982), 3.

6) H. Inagaki: Tetsu-to-Hagané, 72 (1986) S1345.

7) W. B. Hutchinson and K. Ushioda: Scand. J. Metall., 13 (1984), 269

8) K. Ushioda, W. B. Hutchinson, J. Ågren and U. V. Schlippenbach: Mater. Sci. Technol., 2 (1986), 807.

9) N. Takahashi, M. Shibata, Y. Furuno, H. Hayakawa, K. Kakuta and K. Yamamoto: Proc. Conf. on Metallurgy of Continuous-Annealed Sheet Steel, ed. by B. L. Bramfitt and P. L. Mangonon, Jr., AIME, Dallas, TX, (1982), 133.

10) S. Ono, O. Nozoe, T. Shimomura and K. Matsudo: Proc. Conf. on Metallurgy of Continuous-Annealed Shect Steel, ed. by B. L. Bramfitt and P. L. Mangonon, Jr., AIME, Dallas, TX, (1982), 99.

11) W. C. Leslie, R. L. Rickett, C. L. Dotson and C. S. Walton: Trans. Am. Soc. Met., 46 (1954), 1470.

12) B. Seter, U. Bergström and W. B. Hutchinson: Scand. J. Metall., 13 (1984), 214.

13) A. Shimohigashi, M. Yamada, Y. Mizuyama and K. Yamazaki: CAMP-ISIJ, 2 (1989), 820.

14) H. Saitoh and K. Ushioda: ISIJ Int., 29 (1989), 960.

15) A. Shimohigashi, M. Yamada, Y. Mizuyama and K. Yamazaki: CAMP-ISIJ, 2 (1989), 821.

16) T. Nishizawa: Bull. Jpn. Inst. Met., 12 (1973), 401.

17) H. Abe: Memoirs of The Low-Carbon Sheet Steels Research Committee, ISIJ, Tokyo, (1987), 203.

18) M. Hillert, T. Wada and H. Wada: J. Iron Steel Inst., 205 (1967), 539

19) D. E. Coates: Metall. Trans., 3 (1972), 1203.

20) H. Ohtani and T. Nishizawa: Tetsu-to-Hagané, 73 (1987), 152.

(Originally published in Tetsu-to-Hagané, 76 (1990), 1536, in Japanese) 